\title{
$\mathrm{PH} 104_{\text {debate }}$
}

a debate Patrimonio cultural y cambio climático

| coordina Alejandro García Hermida

\section{¿Cómo crees que afecta el cambio climático al patrimonio cultural?}

\author{
Robert Adam | Robert Adam Architectural Consultancy \\ URL de la contribución <www.iaph.es/revistaph/index.php/revistaph/article/view/4997>
}

Esta pregunta debería plantearse en futuro. El cambio climático está presente. Siempre lo ha estado. Pero, aparte de algunos acontecimientos significativos, las principales consecuencias de este son, en gran medida, predicciones.

Esto sucede en todos los aspectos de la vida: tenemos que predecir el futuro más probable para poder sobrevivir. Podemos utilizar medios más avanzados y científicos, pero puede aparecer, y a menudo ha aparecido, un "cisne negro", metáfora utilizada para referirnos a un gran acontecimiento imprevisible. Predecimos un cambio rápido de cierta relevancia en el clima basándonos en la actividad humana del pasado y muchos gobiernos están intentando modificar el comportamiento futuro para mitigar este cambio previsto. Sin embargo, como en todas las predicciones futuras, siempre hay algo de incertidumbre.

El patrimonio no son los objetos físicos o las tradiciones en sí mismas, sino aquello que la comunidad cree que debería representar un pasado significativo para su identidad. Esto está destinado a cambiar. Incluso ahora, se está viviendo este controvertido proceso en lugares como Sudamérica y en otras regiones, donde se están reevaluando aquellas partes de su pasado con las que creen que ya no deberían identificarse.

Todas estas son respuestas sociales al cambio climático y al patrimonio; y no es tanto el cambio climático en sí lo que afectará al patrimonio, como la forma en la que las sociedades reaccionen a cualquier presión para modificarlo o redefinirlo.

El cambio climático podría ser tan grave y convertirse en un imperativo moral de tal calibre que cualquier acti- vidad pasada relacionada con el despilfarro energético se convertiría en objetos o actividades con los que ya no querríamos identificarnos. A pesar de su antigüedad y su ubicuidad, que los convertía en un reflejo de su tiempo, toda asociación con estos objetos o actividades podría ser censuradas. Esto ocurre también con cualquier cosa o persona que haya tenido alguna vinculación con la esclavitud, que cumple con todas estas características, y que es ahora considerada por muchos como ofensiva. Aunque pensemos que esto es poco probable, podemos especular sobre lo que significaría para nuestro patrimonio ya construido.

Todo lo relacionado con actividades como la minería del carbón o la extracción de petróleo, y todo lo financiado por estas actividades, podría dejar de conside-

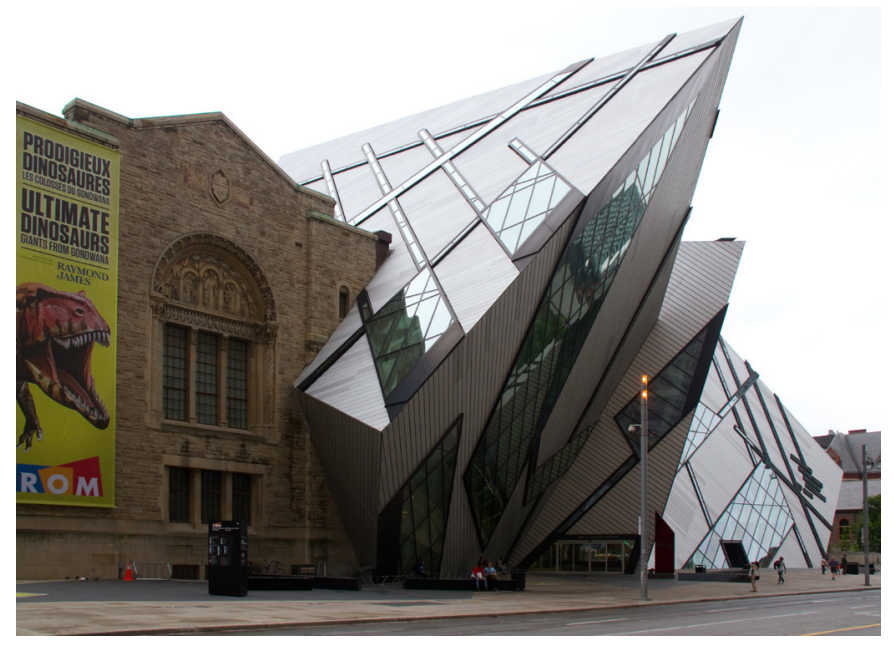

Ampliación del Museo Real de Ontario, Canadá. Daniel Libeskind, 2007. Descrito como "edificios históricos, complementados por una arquitectura atrevida y con visión de futuro", la moda del contraste basada en la teoría del arte-histórico finalmente destruye el valor patrimonial del original | foto Tony Hisget 


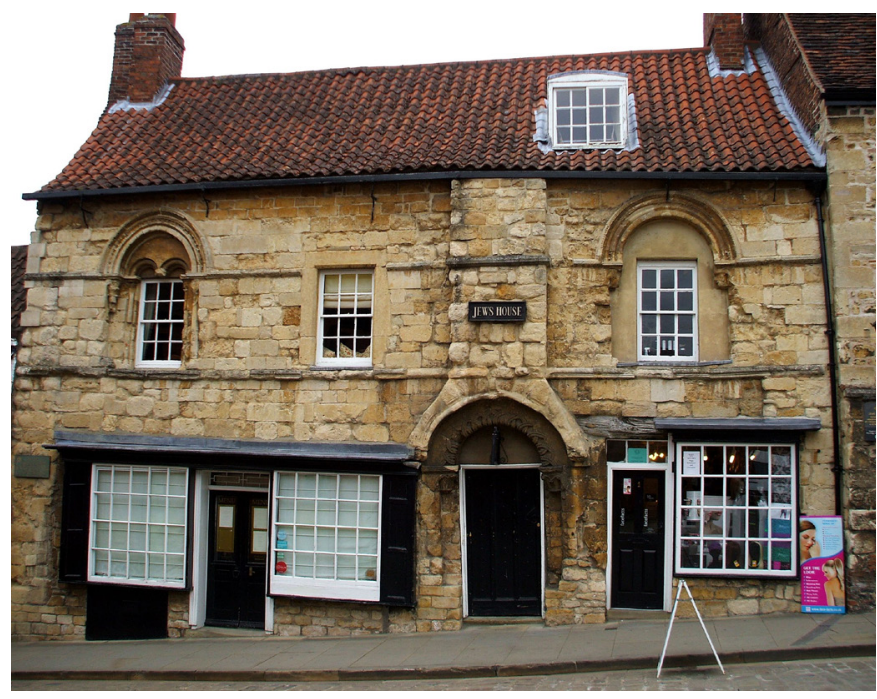

Jews House, Lincoln, Inglaterra. Continuamente ocupado, desde mediados del siglo XII, este edificio ha acumulado una importante cantidad de carbono | foto Marek69

rarse digno de ser llamado patrimonio. El impacto sería enorme. Muchas casas de campo en Gran Bretaña, incluso todo lo que tiene que ver con la Fundación Getty, y hasta lo que ha sobrevivido de la revolución industrial, merecerían la indiferencia, o incluso algo peor.

Un resultado opuesto, también basado en resultados climáticos graves, sería que las consecuencias se consideraran tan extremas que el desorden social y el desastre global provocaran que las comunidades colapsaran. Cualquier cosa que refuerce la identidad y proporcione un recuerdo de épocas mejores y de una localidad concreta tendría una consideración especial. El valor del patrimonio se vería reforzado y los nuevos aspectos o los más recientes del pasado podrían convertirse en patrimonio (como, de hecho, sucede todo el tiempo). Esto es lo más probable y constituiría una aceleración y extensión de la situación actual, donde la globalización tiene que reforzar el interés por lo local y la tradición.

Otra consecuencia del cambio climático extremo ( $y$, de hecho, proyectado) es el desplazamiento demográfico desde zonas recientemente degradadas por la pérdida de tierras productivas, o la subida del nivel del mar, hacia zonas con mejores condiciones agrícolas o más aptas para el asentamiento. Esto ya está ocurriendo. Si los lugares afectados por la deserción tienen un valor patrimonial y han de sobrevivir como lugares aptos para la ocupación, posiblemente de menor tamaño, habrá que crear condiciones económicas viables y considerar la demolición de los edificios sin valor patrimonial actual o probable para consolidar la población restante o entrante en los edificios a conservar. Lo más probable es que esto requiera de un cambio cultural y una acción política. Una de las consecuencias sería la reconsideración de cómo adaptar el patrimonio superviviente.

Actualmente se está debatiendo sobre si se debe mejorar la eficiencia energética cuando los edificios históricos siguen estando ocupados y cómo hacerlo. Esto ya está provocando dificultades. El aislamiento exterior, los paneles solares y el doble o triple acristalamiento se han propuesto como soluciones, pero su impacto en el aspecto de los edificios históricos puede alterar significativamente su apariencia, sobre todo cuando es el registro de la apariencia y el tejido del edificio lo que valida su conservación como patrimonio. Hay dos posibles respuestas a esto.

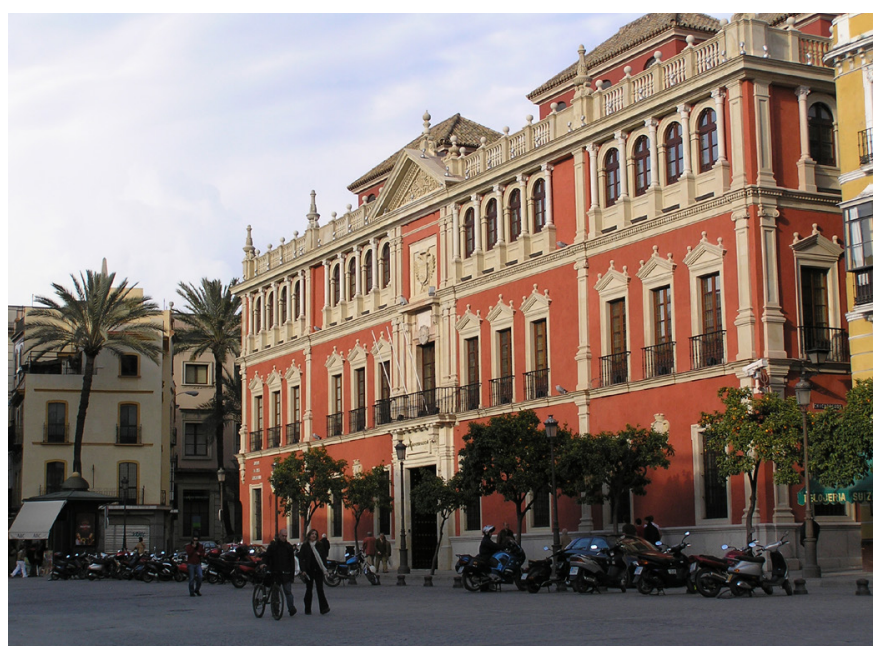

Real Audiencia de los Grados de Sevilla, reconvertida, alterada y ampliada como edificio Cajasol por Rafael Manzano. La alteración y extensión comprensiva de los edificios patrimoniales permitirá una reutilización más eficaz sin destruir el valor patrimonial | foto Dani svq 
La primera es adoptar una visión más evolutiva que preservacionista del patrimonio. Muchos edificios se han conservado en un momento arbitrario de su historia, deteniendo un proceso de cambio que habría continuado si no se hubieran adoptado medidas legales para detenerlo. El problema de muchas de las remodelaciones recientes de los edificios patrimoniales ha sido la naturaleza insolidaria de los materiales modernos, la actual cultura antihistórica de la arquitectura dominante y los principios de la Carta de Venecia de la Unesco, según los cuales las adiciones tienen que ser obvias y claramente "modernas". Una mayor tolerancia al cambio, por el que se mantiene el carácter del edificio, proporcionaría oportunidades para aumentar el rendimiento energético sin destruir o comprometer el valor de la memoria del patrimonio original.

La segunda es reconocer el ahorro de energía que ya está presente en las estructuras existentes. Cientos de años de uso continuado suponen un importante ahorro energético en relación con una estrategia de sustitución, incluso de una discreta. En la actualidad, el ahorro de energía se mide en términos del ahorro en la energía entrante activa que se produce por una mayor eficiencia ante la pérdida de energía en curso. En ninguna parte de estos cálculos aparece una medida acordada que haga referencia a una mayor importancia con respecto a la longevidad, como tampoco aparece en ninguna parte, incluso en las que reconocen el valor de la longevidad futura, ningún crédito para el ahorro de energía de forma retrospectiva.

A pesar de que el ahorro de energía de forma retrospectiva o el crédito energético puedan ser difíciles de aceptar con el concepto de una acción futura para moderar el cambio climático, el principio de que "el edificio más ecológico es el que ya está construido" está ganando cada vez más adeptos. Este principio afectará inevitablemente al patrimonio ya construido. Lo más probable es que tengamos que adoptar una visión más crítica y flexible de la adaptación y la modificación y, por lo tanto, de la integridad del patrimonio, y ofrecer un enfoque arquitectónico adecuado al cambio. 